\title{
ASPEK LINGKUNGAN LOKASI BERTELUR PENYU DI PANTAI TATURIAN, BATUMBALANGO TALAUD
}

\author{
(Environmental Aspects of Turtle Nesting Site at Taturian Beach, \\ Batumbalango Talaud)
}

\author{
Fieter Langinan $^{{ }^{\star}}$, Farnis B. Boneka ${ }^{1}$, Billy T. Wagey ${ }^{1}$
}

\author{
1. Program Studi IImu Kelautan, Fakultas Perikanan dan IImu Kelautan, Universitas Sam \\ Ratulangi,Manado. \\ *e-mail :fieter.langinan@gmail.com
}

Sea turtles have a unique habit in their reproductive cycle which are spawn in location where they hatched, eventhough the beach area are continue to change. Due to this fact, it is necessary to conduct a research to perform inventorization and provide a description of the circumstances where the turtles lay their eggs. Taturian Beach at Batumbalango District is one of sixteen sea turtle nesting area located in Karakelangisland, Talaud Regency .The aim of this study is to provide a description of the turle nesting area in Taturian Beach including geographical position, coastal length, the beach slope, the composition of the sediments and terresterial vegetation around the turtle nesting site. The geographical position is determined by using GPS device, the sediment was analyzed according to the AFNORscale, while the vegetation was documented using photography. The data was descriptively presented. The

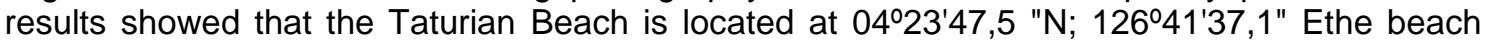
also has a function as a fishing boat moorings; $\pm 100 \mathrm{~m}$ long beach covered with rocky limestone, with 19 to $20 \mathrm{~m}$ wide, the sediments is predominantly moderate sand (44\%)and the beach slope is 4.5 to $9.0 \%$ or can be concluded to sloping ramps up to the slopes criteria. The turtle nesting area is adjacent to residential and also palm plantations. Since the sea turtles declared as protected animals, Taturian Beach should be designated as a turtle conservation area.

Keywords: Environmental conditions, Nesting site, Sea turtles.

Penyu memiliki kebiasaan unik dalam siklus reproduksi yakni bertelur di lokasi di mana mereka ditetaskan, sekalipun wilayah pantai terus mengalami perubahan. Untuk itu, dipandang perlu melakukan inventarisasi dan menyediakan deskripsi keadaan lingkungan tempat bertelur penyu. Pantai Taturian Desa Batumbalango merupakan salah satu dari enambelas tempat bertelur di pulau Karakelang Talaud. Tujuan penelitian ini untuk menyediakan dideskripsi lokasi bertelur penyu di pantai Taturian mencakup posisi geografis, panjang-lebar pantai, kemiringan pantai, komposisi sedimen sekitar lubang sangkar peletakkan telur dan vegetasi darat. Posisi geografis ditentukan dengan menggunakan GPS, sedimen dianalisis menurut skala AFNOR, vegerasi difoto. Data disajikan secara deskriptif. Hasil menunjukkan bahwa pantai Taturian terletak pada $04^{\circ} 23^{\prime} 47,5^{\prime \prime}$ LU dan $126^{\circ} 41^{\prime} 37,1^{\prime \prime}$ BT berfungsi pula sebagai tempat penambatan perahu nelayan; panjang pantai $\pm 100 \mathrm{~m}$ dibatasi tanjung berbatu limestone, lebar pantai 19 $20 \mathrm{~m}$, sedimen yang dominan adalah pasir sedang (44\%); kemiringan pantai $4,5-9,0 \%$ atau termasuk kriteria landai hingga lereng miring. Lokasi ini berbatasan dengan pemukiman dan perkebunan kelapa. Mengingat penyu dinyatakan sebagai zatwa lindung, sepatutnya pantai Taturian ditetapkan sebagai lokasi konservasi penyu.

Kata Kunci :Kondisi lingkungan, Tempat bertelur, Penyu

\section{PENDAHULUAN}

Studi tentang presepsi warga tentang konvervasi penyu di wilayah pulau Karakelang Talaud diperoleh hasil bahwa pada umumnya penduduk lokal pulau Karakelang $( \pm 80 \%)$ belum tahu status penyu sebagai zatwa 
lindung (Langinan, 2015); oleh karena itu, kegiatan penangkapan penyu di wilayah ini masih dilakukan oleh warga untuk diperjual-belikan dan untuk dikonsumsi. Selanjutnya, warga lokal mengenal dengan baik tiga jenis penyu yakni penyu Hijau (Chelonia mydas) atau dalam bahasa lokal Lanno, penyu Sisik (Eretmochelys imbricate) disebut Rusip, dan penyu Belimbing (Dermochelys coriacea) dinamakan Birrang. Adanya nama lokal bagi setiap jenis penyu mengindikasikan status dan nilai biota laut ini dalam kehidupan masyarakat setempat.

Dilaporkan pula bahwa di wilayah pantai pulau Karakelang terdapat 16 lokasi tempat bertelur penyu (Boneka \& Schaduw, 2015). Salah satu lokasi tempat bertelur penyu di pulau Karakelang terletak di desa Batumbalango, Kecamatan Esang Selatan. Pantai ini disebut Taturian, yang dalam bahasa lokal artinya tempat mendaratkan perahu. Pantai Taturian menarik dideskripsikan karena profilnya tidak seperti lokasi bertelur penyu pada umumnya yang mencakup wilayah pantai dengan hamparan pasir yang luas, jauh dari perkampungan.

\section{METODE PENELITIAN}

Penelitian dilakukan di pantai Taturian, desa Batumbalango, Kecamatan Esang Selatan, Pulau Karakelang, Talaud, Provinsi Sulawesi Utara (Gambar 1). Data diperoleh melalui observasi mencakup: (a) posisi geografis, (b) sedimen, (c) lebar pantai, (d) kemiringan pantai dan (e) vegetasi

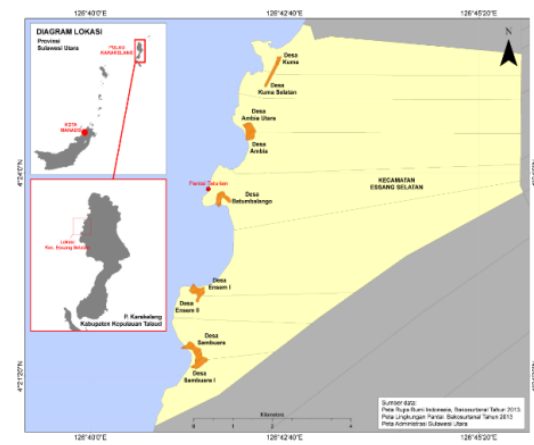

Gambar 1. Lokasi penelitian, pantai Taturian, Kecamatan Esang Selatan, Talaud

Tabel 1. Skala AFNOR (Association Francaise Pour La Normalisaton).

\begin{tabular}{ll} 
Jenis Sedimen & Sedimen $(\mathrm{mm})$ \\
\hline Batu & $>20$ \\
Kerikil & $20-2$ \\
Pasir Kasar & $2-0,8$ \\
Pasir Sedang & $0,8-0,315$ \\
Pasir Halus & $0,315-0,125$ \\
Pasir Sangat Halus & $0,125-0,050$ \\
Debu & $<0,050$
\end{tabular}

darat. Posisi geografis lokasi penyu meletakkan telur diperoleh dengan menggunakan GPS (Global Positioning System). Sampel sedimen diambil pada titik sejajar dengan letak lubang bertelur penyu, yang diduga menjadi lintasan penyu menuju sangkarnya atau kembali ke laut setelah bertelur. Demikian pula sampel sedimen di ambil dari sekitar lubang bertelur penyu. Sedimen dianalisis menggunakan ayakan granulometri dan klasifikasi skala AFNOR (Tabel 1), metode yang umum digunakan untuk studi sedimen pantai (eg. Marasut, 2002; Balaira, 2017). Vegetasi darat didokumentasikan. Data dianalisis dengan metode deskriptif.

\section{HASIL DAN PEMBAHASAN}

\section{Posisi geografis dan ukuran pantai}

Lokasi bertelur penyu di pantai Taturian, Desa Batumbalango, kecamatan Esang Selatan pada posisi $04^{\circ} 23^{\prime} 47,5^{\prime \prime}$ LU dan 126⒋ $37,1^{\prime \prime}$ BT. Terletak berdekatan dengan wilayah pemukiman dan menjadi tempat penambatan perahu nelayan. Bekas lubang bertelur penyu menyebar sepanjang $\pm 100 \mathrm{~m}$, dan lebar di atas 
batas pasang tertinggi sekitar $10 \mathrm{~m}$. Lebar wilayah gisik sekitar 19-20 meter dengan areal pasang surut yang sempit (Gambar 2). Bila dibandingkan dengan

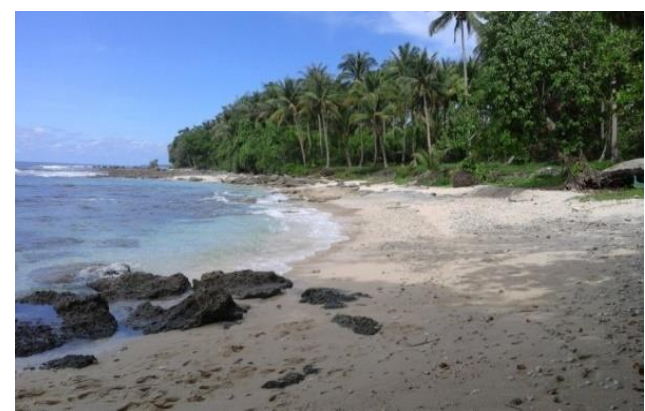

Gambar 2. Lokasi bertelur penyu di Pantai Taturian

pantai tempat bertelur penyu pada umumnya (eg. Kasenda, 2014), maka pantai Taturian ini tergolong sempit.

\section{Kemiringan}

Kemiringan pantai diukur pada dua titik, sejajar dengan letak lubang tempat bertelur penyu. Hasil menunjukkan lokasi ini termasuk kategori landai 4,56\% (Gambar 3A) dan lereng miring 9,00\% (Gambar 3B). Kemiringan lereng gisik merupakan salah satu faktor kesulitan menuju lokasi bertelur dan mempengaruhi kecepatan penyu untuk kembali ke laut setelah bertelur atau menghindar dari situasi yang berbahaya. Semakin curam pantai maka akan semakin besar pula energi penyu yang diperlukan naik untuk bertelur. 


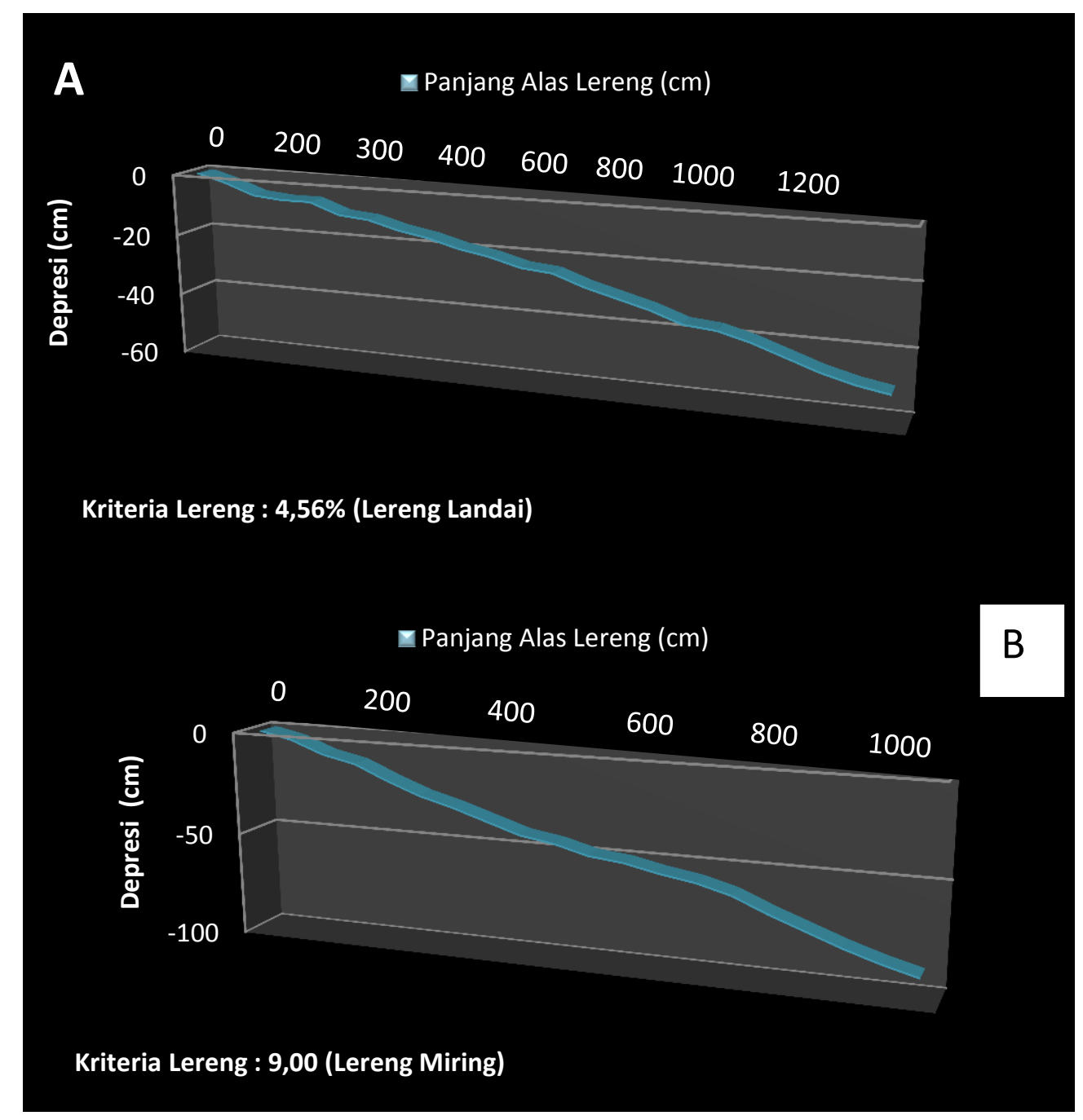

Gambar 3. Kemiringan Pantai Taturian

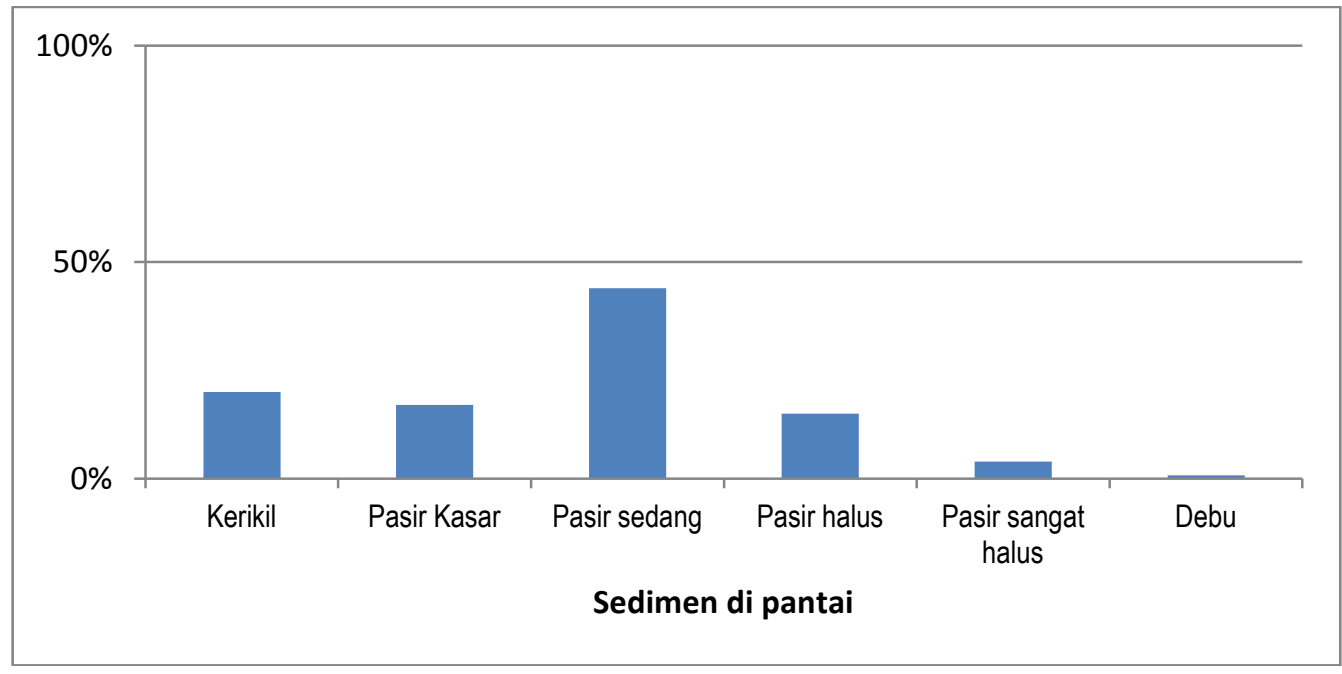

Gambar 4. Komposisi sedimen pada daerah pantai. 


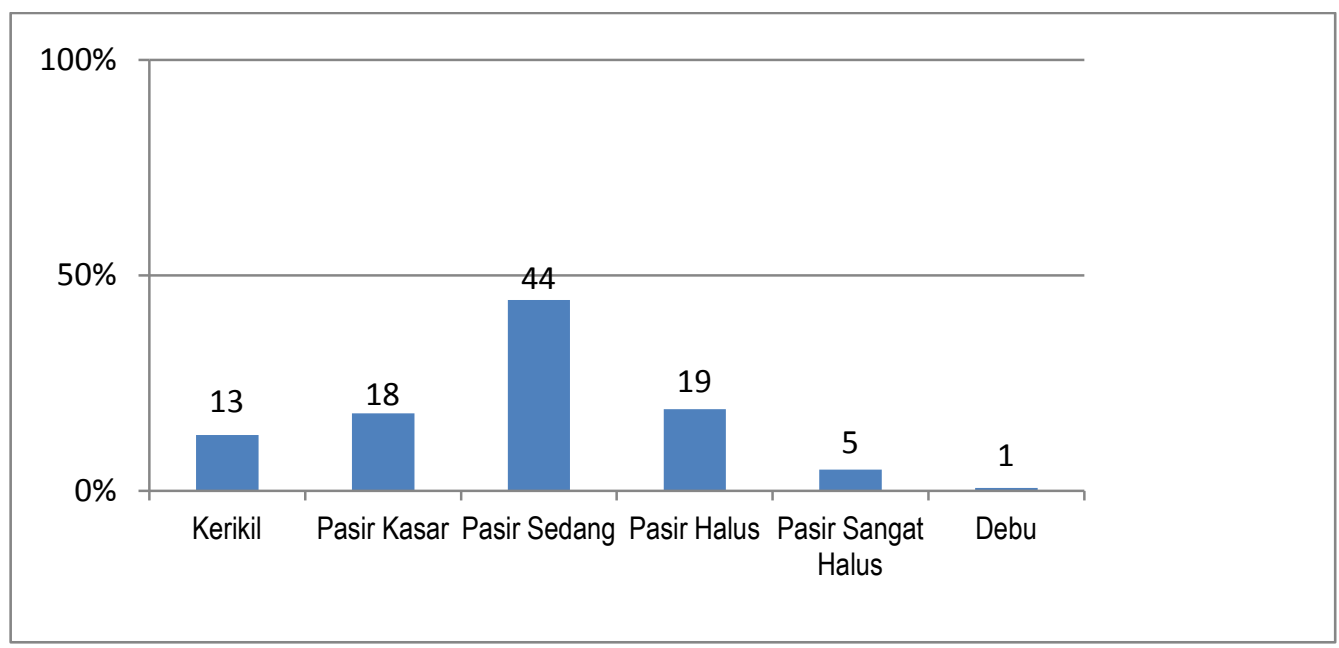

Gambar 5. Sedimen di sekitar lubang bertelur.

\section{Sedimen.}

Penyu meletakkan telur di mintakat supratidal atau di atas batas pasang tertinggi. Sebelum tiba di area lubang untuk meletakkan telur, penyu merangkak naik melintasi mintakat gisik. Jenis sedimen lahan gisik ditunjukkan pada Gambar 4; dengan komposisi terdiri dari kerikil $20 \%$, pasir kasar $16 \%$, pasir sedang $44 \%$, pasir halus $15 \%$, pasir sangat halus $4 \%$ dan debu $1 \%$. Kondisi sedimen pada

daerah lintasan ikut berpengaruh pada kecepatan pergerakan penyu menuju lokasi pembuatan lubang.

Selanjutnya, pada Gambar 5 ditunjukkan komposisi sedimen pada lubang sangkar penyu meletakkan telur didominasi oleh pasir sedang yakni $44 \%$, pasir halus 19\%, pasir kasar 18\% dan pasir sangat halus 5\%. Dengan demikian, lokasi penyu bertelur di pantai Taturian didominasi komposisi pasir sedang $(0,8-0,315 \mathrm{~mm})$. Sedimen di sekitar lubang bertelur penyu diduga memberi kontribusi atau terkait dengan (1) aktivitas menggali lubang oleh induk, (2) mencegah runtuh, (3) resapan air, (4) suplai oksigen dan pertukaran udara, (5) proses keluarnya tukik setelah menetas.

\section{Vegetasi darat}

Lokasi bertelur penyu di pantai Taturian berada di areal perkebunan kelapa, di atas wilayah pasang teringgi. Tercatat tanaman yang dominan adalah kelapa (Cocos nucifera) yang masih produktif, tinggi pohon $\pm 10 \mathrm{~m}$, pandan pantai (Pandanus tectorius) tinggi pohon $\pm 3-5 \mathrm{~m}$, ketapang (Terminalia catappa) tinggi 2-5 $\mathrm{m}$, pohon bitung (Barringtonia asiatica) dengan tinggi 1$2 \mathrm{~m}$. Tumbuhan-tumbuhan tersebut penting berfungsi untuk menjaga dan meningkatkan kelembaban pasir, stabilitas suhu dan mengurangi penguapan akibat radiasi sinar matahari. Nuitja (1992) menyatakan bahwa kelebatan hutan wilayah pantai dan pesisir memberi pengaruh yang baik terhadap kestabilan populasi penyu.

\section{KESIMPULAN}

Pantai Taturian sebagai tempat bertelur penyu di wilayah desa Batumbalango, kecamatan Esang Selatan, merupakan kawasan yang relative sempit, dengan kemiringan pantai landai hingga sedang, terletak 
dalam wilayah pemukiman dan perkebunan kelapa. Sedimen yang dominan di sekitar lubang bertelur termasuk dalam kategori pasir sedang

\section{UCAPAN TERIMA KASIH}

Artikel ini adalah bagian dari Skripsi mahasiswa yang diajukan untuk menyelesaikan pendidikan Strata S1 di Program Studi IImu Kelautan, FPIK Unsrat. Penulis menyampaikan terima kasih kepada pimpinan Fakultas perikanan dan IImu kelautan Unsrat atas arahan, dan kepada tim penguji dan editor jurnal atas saran dan koreksi pada tulisan ini.

\section{DAFTAR PUSTAKA}

Anonim. 2009. Pedoman Teknis Pengelolaan Konservasi Penyu. Diterbitkan oleh Direktorat Konservasi dan Taman Nasional Laut, Direktorat Jenderal Kelautan, Pesisir dan Pulau-Pulau Kecil, Departemen Kelautan dan Perikanan RI

Balaira, E. 2016. Kendala Konservasi Penyu di Pulau Salibabu Kabupaten Talaud. Laporan Praktek Kerja Lapang (PKL), Fakultas Perikanan dan IImu Kelautan, Universitas Sam Ratulangi, Manado

Balaira, E. 2017. Lokasi bertelur penyu di pulau Salibabu, Talaud (in press).
Boneka, F.B., Schaduw, J.N. 2015. Inventarisasi tempat bertelur di Kepulauan Talaud. Laporan akhir RUPT Unsrat.

Langinan, F. 2015. Persepsi Masyarakat Tentang Konservasi Penyu di Pulau Karakelang Kepulauan Talaud. Laporan PKL, Fakultas Perikanan dan IImu Kelautan, Universitas Sam Ratulangi. Manado.

Marasut, Y.S. 2002. Morfometri dan Granulometri Sedimen Lahan Gisik di Kawasan Pantai Teluk Manado. SKRIPSI. Fakultas Perikanan dan IImu Kelautan UNSRAT. Manado

Nuitja, I.N.S. 1992. Biologi dan Ekologi Pelestarian Penyu Laut. IPB Pres, Bogor

Romimohtarto, K. Juwana, S. 2001. Biologi Laut: IImu pengetahuan tentang biota laut. Djambatan, Jakarta.

Sunarto. 1991. Geomorfologi Pantai. Pusat Antar Universitas. Universitas Gadjah Mada. Yogyakarta 